\title{
Journey of Change: A Summative Assessment Transformation
}

Karen A. Fallon

Towson University, kfallon@towson.edu

Diana C. Emanuel

Towson University, demanuel@towson.edu

DOI: https://doi.org/10.30707/TLCSD3.1Fallon

Follow this and additional works at: https://ir.library.illinoisstate.edu/tlcsd

Part of the Communication Sciences and Disorders Commons

\section{Recommended Citation}

Fallon, Karen A. and Emanuel, Diana C. (2019) "Journey of Change: A Summative Assessment Transformation," Teaching and Learning in Communication Sciences \& Disorders: Vol. 3: Iss. 1, Article 1. DOI: https://doi.org/10.30707/TLCSD3.1Fallon Available at: https://ir.library.illinoisstate.edu/tlcsd/vol3/iss1/1

This Scholarly Teaching is brought to you for free and open access by ISU ReD: Research and eData. It has been accepted for inclusion in Teaching and Learning in Communication Sciences \& Disorders by an authorized editor of ISU ReD: Research and eData. For more information, please contact ISUReD@ilstu.edu. 


\title{
Journey of Change: A Summative Assessment Transformation
}

\begin{abstract}
Abstract

Program review indicated the need for substantive change in a summative assessment process for a speech-language pathology graduate program. A group dynamics approach was used to facilitate change that involved an emphasis on quality culture and faculty input. The result was a productive and collaborative journey of transformation resulting in a more time-efficient and valid summative evaluation of student knowledge and skills.
\end{abstract}

Keywords

summative assessment, graduate program

Cover Page Footnote

N/A 


\section{Introduction}

University clinical programs provide extensive outcomes documentation to internal and external constituents including assessment committees, accreditation and certification agencies, and state licensure boards. Time-consuming assessment processes are housed within academic environments in which the past decade has seen marked increases in media scrutiny of college costs (e.g., Clark, 2016; Dickler, 2016) coinciding with increased faculty workload, salary compression, and cost containment measures (American Association of University Professors, n.d.; Massy, 2013). Program directors must keep programs nimble enough to meet changing workforce demands and accreditation standards while simultaneously respecting academic freedom of faculty and optimizing productivity. This requires constant assessment and change. Even incremental changes within an organization are met with resistance (Lorenzi \& Riley, 2000); however, with effective leadership, changes can occur. One such change process is described here; a specific weakness was identified via action research and a series of leadership steps facilitated collaborative problem solving and a focus on shared governance and quality culture. The result was improved efficiency and quality of a comprehensive examination process. We assert that other graduate programs are in a similar position; that is, a need for substantive change in various processes (e.g., to meet new Council on Academic Accreditation standards [CAA, 2017]) in concert with faculty who are resistant to change. The focus of this paper is to describe the leadership steps that facilitated the change process and to share the perspectives of various stakeholders, including faculty, program director, chairperson, and students.

\section{Prelude to the Change Process}

Background. The journey of change began with the simultaneous appointment of a new speechlanguage pathology (SLP) graduate program director ("director") and department chairperson ("chairperson"). For the program described here, the director has delegated authority from the chairperson to provide semi-autonomous management of the graduate program, including some faculty management tasks, curriculum development, admissions, assessment, and student advising. The chairperson has oversight of all programs within the department (in this case four), and serves as the supervisor of all faculty and staff, budget officer for the department, and manager of most departmental functions. The initial focus of the director and chairperson was improving the efficiency of time-intensive administrative processes using action research.

Action Research Part 1: Identification and Examination of a Problem. Action research originated in the mid-1940s when researchers applied the scientific method to educational practice (Masters, 1995). It is currently defined as "a wide variety of evaluative, investigative, and analytical research methods designed to diagnose problems or weaknesses - whether organizational, academic, or instructional - and help educators develop practical solutions to address them quickly and efficiently" (Great Schools Partnership, 2015, para. 1). Action research involves: (1) the identification and examination of problems based on myriad input, (2) initiation of a change process, (3) examination and dissemination of outcomes, and (4) continued examination.

The new chairperson was appointed during a transition period in which tenured and tenure-track faculty were required to move from a 6-unit teaching load to a 7-unit teaching load. In order to 
facilitate this transition, the chairperson worked with directors to identify educational processes in which efficiency could potentially be improved, as long as careful consideration was given to maintaining the quality of the outcome. This process naturally led to the use of action research. For the speech-language pathology program, action research was used first for the investigation of the summative graduate comprehensive examination because of the tremendous time requirement across all faculty in the program, especially the director. Optimally, this type of examination provides summative assessment for individual students and, in the aggregate, serves to identify programmatic strengths and weaknesses so as to inspire changes that will benefit future students (Banta \& Blaich, 2011; Castleberry, Schneider, Carle, \& Stowe, 2016; Meek, Runshine, Young, Embree, \& Riner, 2015; Smith \& Eder, 2001; Yin \& Volkwein, 2010). These objectives were not met with the long-standing graduate comprehensive examination, which was poorly constructed and had an unusually high administrative burden. Although the high administrative burden was the initial focus of the action research, the low quality of the examination process quickly became the more important issue to address.

Content and Format Issues. The traditional examination was a two-day, paper-based, mixedformat, summative examination with eight clinical topic areas. Students were required to pass the examination (passing score $=80 \%$ ) in order to graduate and they were allowed a maximum of three attempts to obtain a passing score or they faced dismissal from the program. Questions were written and graded by multiple faculty members, who had control of content and question format (e.g., essay, short answer, multiple choice, etc., or multiple formats). The mixed format within and across topic areas resulted in an examination that appeared to be "cobbled-together" - in other words, carelessly assembled from random parts. Electronic survey responses from students and alumni indicated the examination was an inaccurate assessment of their knowledge and skills and it served as an undue source of stress because of inconsistencies in question format, clarity, length, and quality. There was a mismatch between individual student failures and the metrics from many other sources including course-based and overall grades; on-campus and off-campus clinical knowledge and skills ratings; Praxis examination scores; performance in oral and written work in didactic courses; and demonstration of knowledge and skills by individual students when required to participate in mentoring following a failed examination.

Administrative Burden and Faculty Time. The examination was associated with a high administrative burden for the director and a large time commitment for faculty. For each administration of the examination, the director had to solicit eight sets of questions from faculty, assemble a single exam, schedule and proctor the exam, copy the exam (in case one or more of $320+$ exam portions were lost), separate and distribute the completed exams to faculty, collect grades for each question, calculate total grades, disseminate pass/fail results, advise students, and assign mentors for half of the cohort ( 20 students per year, due to a $45 \%$ to $56 \%$ initial failure rate between 2010 and 2015). This was then repeated one to two more times for each cohort, with approximately 20 and 6 students requiring a second and third attempt, respectively, with an eventual pass rate of $100 \%$ for all students, by the third attempt. Faculty procrastination or illness at any point in the process was problematic and resulted in many last-minute tasks for the director. From the faculty perspective, substantial time was required for creation of two to three unique sets of questions per year, grading of questions, and mentoring. The pressure from students to be "mentored to pass the test" was pervasive and often created a negative attitude towards the 
mentoring process by both students and faculty. Mentoring was perceived as punitive, instead of supportive.

Leadership Summary of the Problem. Based on the information provided above, the director and chairperson believed they had clearly identified a problem and the evidence they examined led to three areas of concern:

1. Questionable reliability: Why would the pass rate double between first and final attempts, based on short-term mentoring for students at the end of a two-year program?

2. Questionable validity: Why were examination results so disparate from other metrics?

3. Questionable utility: Could the process be changed so it would fulfill the purpose of a summative assessment but with improved efficiency?

A review of the literature indicated problems with reliability, validity, and utility are endemic to "locally developed" summative exams (e.g., Yin \& Volkwien, 2010). Locally developed exams are created by individual faculty, programs, or schools and they are not subjected to the same level of scrutiny or oversight as examinations developed by regional entities (e.g., state education systems), professional testing services (e.g., the Educational Testing Service [ETS], which administers the Praxis exam), or national professional associations (e.g., National Council of State Boards of Nursing). Although examinations developed nationally are well constructed, they should not be used in lieu of program-based summative assessment, which is specifically created and validated for specific learning outcomes. For example, ETS cautions users that the validity of each test is restricted to the use associated with the construction of that test (e.g., GRE specialty tests should not be used as a requirement for conferral of a degree [ETS, 2018]).

Action Research Part 2: Initiation of a Change Process. Once a problem has been identified and examined, a change process is the next logical step; however, if this change process is driven from a single person's perspective, the change process can be difficult (Murphy, 2016). Resistance to change within any organization can be a challenge. In an academic environment, it is especially difficult to affect change because academic freedom is a basic tenet. Academic freedom is associated with societal trust that faculty will deliver quality education with relatively little oversite; however, this trust has eroded over the past several decades and it has been partially supplanted with external accountability requirements (Yingqiang \& Yongjian, 2016), which are generally disliked by faculty, who prefer to rely on their own internal motivation and professionalism to drive continuous quality improvements in their teaching (Huisman \& Currie, 2004).

Academic freedom includes the proviso that faculty have the right to grade student work and maintain academic standards within their subject matter (Nelson, 2010). In response to external pressure to centralize student grading, it is natural to expect resistance because of the perceived and actual shift of power from individual faculty to a centralized process (Sadler, 2011). This shift may have a negative impact on faculty perception of their autonomy, faculty morale, and teaching innovation (Gosling \& D'Andrea, 2001). In some cases, researchers note a shift in power from faculty to external entities results in a superficial indication of compliance from faculty, with a simultaneous hidden effort towards non-compliance (Anderson, 2006). Effective leaders predict this natural tendency of faculty and work with faculty to create an environment that values open discussion and focuses on development of a "quality culture" (Yingqiang \& Yongjian, 2016). 
Quality culture can be described as an organizational culture in which shared values guide change. Faculty working together using collaborative problem solving, with a shared focus on the quality of the "product" they are developing, can more easily resolve conflicts, combine efforts to gather information, and reach mutually agreeable resolutions to the benefit of the organization (Gray, 1989). Collaborative problem solving aimed at consensus building is preferable to top-down decision making when the goal is group support for change (Hanson, 2005; Innes, 1996; Innes \& Booher, 1999a; Mason, Holley, Wells, Jain, Wuerzer, \& Joshi, 2016; Susskind, McKearnan, \& Thomas-Lamar, 1999); however, it takes time, effort, and creativity to effect change that includes attention to diverse opinions.

\section{The Change Process Itself}

Initial Meeting with Faculty (December, 2014). In December 2014, the director introduced concerns regarding the examination to the speech-language pathology faculty for the first time, at a program-level meeting ("program meeting"). Program meetings are led by the director and include all faculty who teach or supervise in that program. The chairperson does not attend. Faculty response indicated that approximately $50 \%$ of faculty wanted to keep the current system in place. Faculty comments during the discussion included the following: there was no need for change, a mixed-format exam was preferred because it can be tailored to the content area, and the creation of a new examination would take a lot of time. As a result of the generally negative response from faculty, the director tabled (put on hold) the agenda item and subsequently met with the chairperson to discuss future leadership steps. Together, they discussed strategies to foster open communication and engage faculty in the process of action-based research. The plan included the development of talking points associated with faculty comments, data associated with the examination, potential solutions, and a discussion of how a potential change process could focus on quality outcomes that support the needs of faculty, director, and students.

Framework for Subsequent Meetings. Following leadership planning, a series of nine program meetings, facilitated by the director, resulted in the creation of a new examination process. Between each meeting, the director met with the chairperson to discuss conflict management strategies and potential ways to integrate diverse faculty opinions into a single workable solution that would have the support of the faculty. Throughout the change process, the targeted goals were to inspire faculty motivation, optimize participation, and increase support for a change process that focused on a quality outcome (Bird, 2001; Forsyth, 2010, Innes, 1996; Innes \& Booher, 1999b). Specifically, a step-by-step approach described by Bird (2001) was applied to the change process as follows: the director clarified the values of the faculty members by facilitating a focused discussion, developed cohesion through the creation of shared goals that could be achieved within a reasonable time-frame, facilitated the selection of several targeted goals by faculty, and motivated faculty to participate in meeting these goals.

The nine program meetings included all full-time faculty (including the director), tenure-track, and clinical faculty in the SLP program, and the SLP Clinical Director staff person ( $n=10$ until August 2015; $n=11$ beginning in September 2015 as a result of a tenure-track faculty hire). Faculty except the new hire had between one and eight years of experience with the paper-based exam process. Throughout the nine, 90-minute, program meetings, faculty were invited to discuss their opinions in an open discussion format with ground rules for discussion as follows: faculty were allowed sufficient time to express personal views, faculty were expected to demonstrate civility, and faculty were expected to listen to the opinions of others without interrupting. 
Meeting 1 of 9: Data and Collaborative Problem-Solving Discussion (February, 2015). The director put the comprehensive examination back on the program meeting agenda in February, 2015, this time doing the following: (a) providing a general overview of the outcomes data associated with the current exam and (b) emphasizing the need for collaborative analysis, creative problem solving, and consensus building (Gray, 1989; Hanson, 2005; Raiffa, 2003). From this point onward, the director acted as facilitator. Discussion was facilitated on each of the above items. Faculty were invited to share comments, suggestions, experiences, and opinions. Minutes from the discussion were taken by the director. The director concluded the meeting with an oral summary of the discussion and the agenda for the next discussion, including follow up on the faculty perspectives shared during this meeting.

Meeting 2 of 9: Faculty Perspectives on Time and Administrative Burden (February, 2015). A second meeting focused on individual perspectives surrounding faculty time and administrative burden. Specifically, the director solicited faculty response to: (a) faculty time required for individual mentoring following exam failure by a large number of students, (b) faculty time required for writing and grading multiple versions of the exam every year, (c) administrative time required by the director to administer the exam, (d) difficulty of the director in justifying the high initial failure rate to administrators, especially in light of $100 \%$ subsequent pass rate within a few weeks, and (e) legal and ethical issues associated with the potential dismissal of students from the program based on a locally-developed examination with questionable validity.

Faculty acknowledged the substantial time commitment associated with the creation of multiple exam questions and mentoring half of the students following initial exam failure. They discussed the potential time reduction associated with the use of test banks with consistent question format. Faculty discussion regarding the need to mentor students who failed, but who clearly understood the material, led to a possible solution, which was the creation of a peer-review process to optimize question validity. Faculty complaints regarding students who wanted to be "taught to the test" were discussed, with a focus on how the development of a consistent question format may assist in managing student expectations, focusing student preparation, and reducing student stress level. Faculty concern regarding their inability to select the question format was considered and juxtaposed with the advantages of removing faculty from the responsibility to select a question format, including the previously mentioned advantages to students and faculty, but also possible reduction in faculty stress level.

By the end of this meeting, the director surmised that faculty were amenable to substantive change in the exam format and process. Although a formal vote was not taken, for the first time in the process, no faculty member expressed the view that they would like to retain the traditional exam format. Instead, the discussion had evolved from one of "if" the exam would change, which was the tone from prior meetings, to "how" it would change, which continued throughout the remainder of the meetings.

Meeting 3 of 9: Implementation of Change (April, 2015). A third meeting included recording of formal faculty consensus that the program would change the exam (100\% agreement). At the beginning of meeting 3, a formal ad-hoc Summative Assessment Committee was created for purposes of workload credit. The ad hoc Summative Assessment Committee created its official 
charge, which was to develop a formal procedure for a new comprehensive exam. At this point, faculty were in formal agreement that a change would occur but specific changes to the exam and the exam process had not been determined.

Meetings 4 through 6 of 9: Setting and Meeting Goals (May, 2015 and September, 2015). The fourth and fifth meetings occurred in May and the sixth meeting occurred in September of 2015, as faculty were employed on a 10-month academic contract. Meeting goals included drafting a policy to describe the process for submission of exam questions, peer-review, exam administration, rules for passing and re-taking the exam, scoring procedures, and so forth. Each drafted decision of a policy or procedure was disseminated electronically and faculty were provided with opportunities to comment electronically and during meetings. Examples of policy decisions included the following:

- Each faculty member who taught the graduate course in the 10 content areas of the new exam would submit 30 questions per content area. This would result in an initial test bank of 300 questions.

- Two sub-groups were formed for the purpose of peer review: pediatric-centered and adultcentered. For lifespan topics such as fluency and voice, faculty self-selected group membership according to their primary area of research, clinical specialization, and/or teaching specialties. For example, the voice professor also taught the adult motor speech class, so she selected the adult topics group, and that group developed voice questions. The AAC instructor had primary clinical specialization in pediatrics, AAC, and children with autism, so she selected the pediatric group and the pediatric group developed AAC questions.

- All submitted questions were subjected to peer review by the sub-group in which the questions were developed.

Meetings 7 and 8 of 9: Peer Review (October, 2015). For the seventh and eighth meetings, the two sub-groups met separately to complete sub-group peer review of submitted questions. Initially, the two sub-groups had different opinions of the format for the review, with the pediatric group using two, in-person review meetings with an item-by-item question review format. Specifically, each faculty member presented his or her questions via Power Point, the sub-group discussed each question and provided constructive feedback regarding content, syntax, clarity, and foils. The adult group at first attempted an expedited process with private review of all test items prior to the meeting to expedite the approval, assuming little discussion would be needed in the sub-group meeting. However, communication between members of the pediatric and adult sub-groups indicated extensive sub-group review had substantial value, both on the creation of final questions, and on mentoring between senior and junior faculty, in the area of assessment. The director formally requested that the adult group review process be modified so it was identical to the pediatric group. Because of the feedback between groups, this request was honored.

Meeting 9 of 9: Exam Administration Process (November, 2015). The ninth meeting was the final process summary meeting before the launch of the new examination, set for January of 2016. In this meeting faculty discussed and came to consensus about test administration specifics including decisions such as: (a) would students would be allowed to skip questions and return to answer them or would they be required to answer each question as presented? (b) Would the test shut down after the allotted three hours had expired? (c) Would students immediately see their 
score upon completion of the exam? (d) Would students be allowed to pause the test in order to use the restroom or get a drink? Faculty discussed each of these issues and used their collective experience as educators to determine the specific processes. Faculty came to consensus relatively quickly on all technical issues. For example, faculty decided students would not be able to skip questions (emulating the Praxis administration rules); the exam proctor would stop the testing at three hours rather than using an electronic timer; students would not see their scores immediately; and the test could be paused for an individual student who required a restroom break.

\section{Change Process Outcomes and Discussion}

Examination Launch. At the completion of the question construction process, there were 300 total questions, including 30 in each of the following content areas: (1) language development/disorders birth to 5 years, (2) language development/disorders for school age, (3) speech-sound disorders in childhood, (4) fluency, (5) dysphagia, (6) cognitive linguistics I (aphasia), (7) cognitive linguistics II (dementia, TBI, etc.), (8) adult neuromotor speech, (9) autism spectrum disorders, and (10) augmentative and alternative communication (AAC). (Please see Appendix A for sample questions). The director worked with the Office of Technology Services (OTS) to load the questions into the Blackboard platform, so each student would receive a unique examination from the test bank consisting of 150 total questions, with 15 questions in each of the subject areas. The director took the examination three times to check for technical glitches before approving the test for launch.

On January 15, 2016, forty-four students took the exam in a computer-based classroom with a time limit of three hours for the test. The exam was proctored by the director and one faculty member. The time required by students to complete the exam ranged from 1.5 to 3.0 hours. The exam process went smoothly overall with only two glitches. One computer malfunctioned and shut down in the middle of the exam. However, the BlackBoard software saved the exam data and the student was able to continue without incident once logged on to a new computer. Secondly, some students reported an occasional repetition of questions ( $n=1-3$ duplicate questions in seven of the student exams). It was later determined that the cause of this glitch was Blackboard's tendency to sample with replacement. Students were informed of this potential and told to proceed if they received a duplicate question.

Action Research Part 3: Evaluation of Revised Process. An overview of the process subsequent to the launch of the new examination provided early indicators of success. Most notably, 38 (86\%) of the students passed the exam in 2016 on the first attempt and the remaining six students passed on their second attempt. This improved to $91 \%$ on the first attempt, in 2017. This represents a significant improvement over the previous two years when an average of $49 \%$ of the students passed the comprehensive exams on the first attempt. This improved success rate had a positive impact in the area of utility, by decreasing faculty time required for mentoring. In contrast to the need in prior years for approximately half the cohort ( 20 students) to be mentored and re-tested, only six students required mentoring and re-examination. Another positive outcome of the process was the reduced time between examination completion and delivery of the examination result, by virtue of computerized scoring and dissemination using the Blackboard platform. The timeliness of exam results and high pass rate most likely resulted in reduced student stress levels, although this was not measured and can only be assumed. 
Student failures which had heretofore been disassociated with other metrics, were much more closely aligned. Student performance on the revised comprehensive exam (86\% first time pass rate) aligned much more closely with outcomes from the national Praxis exam overall (100\% first time pass rate), course grades, clinical skills ratings, and faculty assessment.

To gauge student perceptions about the revised exam, student feedback was requested by the director via an email survey after the 2016 exam. Approximately $75 \%$ of graduate students who took the exam provided comments that suggested a high level of satisfaction overall. The most frequent student comments indicated a positive response to: the multiple choice format $(n=18)$, grouping of test questions by content area $(n=6)$, computerized test format $(n=5)$, and timely dissemination of results $(n=4)$. The most common suggestion for improvement was for the system to allow students to go back to previously answered test questions $(n=15)$. Student feedback was reviewed by the faculty and will be used for future changes to the exam.

Faculty feedback was gathered by the director via an email survey asking for feedback concerning: 1) what faculty liked about the new comprehensive exam system and 2) what the faculty would like to see change in upcoming years. Faculty responses indicated the students who failed the new examination had weaknesses that were clearly evident during the mentoring process. Overall, faculty responses regarding the new format were overwhelmingly positive regarding the reduction in workload time, speed of scoring, and speed of results dissemination. Faculty stated their initial reaction to the group peer review of questions was that it was intimidating. However, at the end of the process, they reported that their colleagues were respectful and the process was extremely valuable in their professional development. Specifically, faculty reported that the process benefitted their test question construction skills, refreshed their knowledge about various content areas, improved their overall attitude towards assessment, instilled a sense of community ownership of the examination process, and resulted in a better summative assessment process. They also appreciated the time saved every year by re-using the test bank and the time saved in mentoring of students who failed but subsequently demonstrated mastery of the material during mentoring sessions.

Action Research Part 4: Continued Examination. The journey of transforming the summative assessment process in this SLP MS program yielded several important insights about consensus building. As with any change in a long-existing process, the support of key stakeholders is critical to the success (Bird, 2001; Yin \& Volkwein, 2010). Initial discussions with faculty about potential changes to the summative assessment process indicated resistance to change, with faculty indicating a desire to maintain the status quo in the areas of format and control over their portion of the examination. This initial resistance to change is a natural and well-document phenomenon within large organizations (e.g., Murphy, 2016; Piderit, 2000). The difficulty was the balance the director needed to maintain between respect for faculty academic freedom, which had resulted in a natural sense of "ownership" for specific topic areas, and the needs of students and program for an improved examination. Logically, it appeared easy to use a top-down perspective to point out problems caused by lack of peer-review, lack of centralized oversight, time requirements, and misalignment between outcomes and other measures. However, logic does not trump the natural inclination of individuals to be resistant to external pressure (Kezar, 2012; Murphy, 2016), to need time for evolution of response (Piderit, 2000), and the inclination of faculty to be part of the change process. Creating a culture of quality is developed optimally by considering diverse faculty 
opinions and working collaboratively to develop a solution to a problem (Yingqiang \& Yongjian, 2016).

Although initial results indicate improvements across all areas identified by administrators and students, continued evaluation of short-term and long-term outcomes is necessary. A process for periodic review and updating of the test bank will be necessary. Future alumni surveys should ask for feedback on the process and its applicability to skills required for the workplace. On-going action research should continue to survey students and faculty regarding strengths and weaknesses in the exam process. In addition, there is always the potential for bias in the interpretation of student survey results. As such, the survey results will be reviewed by a larger number of faculty and other metrics will be examined in comparison with examination results, to more closely examine validity.

\section{Implications for Graduate Programs}

The current project serves as an example of how substantive and effective change can occur as a result of applying action research and collaborative problem solving in academia. Program assessment, as a general rule, is met with little enthusiasm and much resistance. For most, it is a task completed according to the mandates of an accrediting organization. It may be viewed by faculty as a tedious task with little inherent reward. The current study suggests the usefulness of applying program data to assist in the change process, but also the importance of patience and time, in a change process. The entire process was completed over a two-year period. Resistance to change was not overcome with urgency or force. Although there was not $100 \%$ consensus on all topics of discussion, the director facilitated an atmosphere of respect and recognized the importance of consensus-building as a journey, approached with an emphasis on collaboration and respect. Suggestions to directors who encounter a similar need to revise faculty-controlled or much-beloved processes are advised to consider the following:

- Anticipate resistance to change. A director/change agent needs to consider faculty resistance to change as a natural human tendency and not a personal attack on their leadership.

- Discuss programmatic problems with supporting data before announcing or beginning a change process, allowing time for faculty to process the information before acting. Do not expect to announce the need for a change and launch into change mode during the same meeting time. Faculty need time to ponder "What is not working" well in advance of "How will we fix it?"

- Be aware of bias in the data used to support the need for a change process. This bias can influence the data at three critical stages of action research: (a) when the action research is planned (pre-trial bias), during data collection (trial implementation), and after data collection (data analysis/summary) (Pannucci \& Wilkins, 2010). For example, survey questions can be written so as to lead a student to respond a certain way or thematic elements extracted from qualitative data may be interpreted to support a specific hypothesis.

- Meet individually with faculty. One on one communication between director and faculty may ease the change process, allow faculty to have dedicated time with the director to voice concerns, and allow the director to build a constituency outside of the group setting. 
- Realize that the viewpoint of the director (chair, dean) is only one viewpoint. What may appear, initially, to be the most logical solution from an administrative point of view may not be viewed that way by faculty. Directives from the top down may fail to gain the necessary support for effective change to occur.

- Be respectful of diverse faculty views and be prepared to listen. Be prepared to stay silent, even when faculty opinions do not align with yours. Consider pledging to faculty that the director will spend the entirety of one meeting listening and taking notes, and not rebutting or judging individual faculty comments.

- Realize that faculty may need time to adjust to the concept of change. Plan for largescale change processes to take over a year. This should be considered when administrators are making long-term and short-term goals.

- Be willing to change pre-conceived change plans after listening to faculty. Most administrators have at least a preliminary plan in mind when approaching a problem. Be aware of this bias and be open-minded enough to accept that others may have a better way to solve a problem. It may be useful, after taking notes from faculty on their opinions, to delay a second meeting until faculty and directors have had sufficient time to consider the issue. It is also useful to prompt faculty to provide any additional thoughts via email. Time sometimes results in new ideas, which may dominate a follow up meeting if an earlier outlet is not provided.

- Continue to gather information and be willing to make changes even after a successful change process.

- Reward faculty for their efforts. In administration, it is tempting to finish one project and move on to the next without appropriate acknowledgement of faculty effort. Public recognition of faculty who put in time and effort to make a change occur is important.

\section{References}

American Association of University Professors. (n.d.). Faculty work and workload. Retrieved from https://www.aaup.org/issues/faculty-work-workload

Anderson, G. (2006). Assuring quality/resisting quality assurance: Academics' responses to 'quality' in some Australian universities. Quality in Higher Education, 12, 161-73. doi:10.1080/13538320600916767

Banta, T. W., \& Blaich, C. (2011). Closing the assessment loop. Change: The Magazine of Higher Learning, 43(1), 22-27.

Bird, A. M. (2001). Faculty buy-in to assessment activities: A group dynamics approach. Assessment Update, 13(1), 6.

Castleberry, A. N., Schneider, E. F., Carle, M. H., \& Stowe, C. D. (2016). Development of a summative examination with subject matter expert validation. American Journal of Pharmaceutical Education, 80(2), 1-9.

Clark, K. (2016, October 26). College prices hit new record highs in 2016. Retrieved from http://time.com/money/4543839/college-costs-record-2016/

Council for Clinical Certification in Audiology and Speech-Language Pathology of the American Speech-Language-Hearing Association. (2013). 2014 Standards for the Certificate of Clinical Competence in Speech-Language Pathology. Retrieved [5/30/2016] from http://www.asha.org/Certification/2014-Speech-Language-Pathology-CertificationStandards/. 
Council for Clinical Certification in Audiology and Speech-Language Pathology of the American Speech-Language-Hearing Association. (2016). 2017 Standards for the Certificate of Clinical Competence in Speech-Language Pathology. Retrieved [5/30/2016] from http://www.asha.org/Certification/2014-Speech-Language-Pathology-CertificationStandards/.

Council on Academic Accreditation. (2017). Standards for accreditation of graduate education programs in audiology and speech-language pathology. Retrieved [01/23/2018] from https:/caa.asha.org/wp-content/uploads/Accreditation-Standards-for-GraduatePrograms.pdf

Dickler, J. (2016, July 14). College costs are out of control [Web article]. Retrieved from https://www.cnbc.com/2016/07/12/college-costs-are-out-of-control.html

Educational Testing Service (2018). Guidelines for the use of GRE scores. Retrieved from https://www.ets.org/gre/institutions/scores/guidelines/

Forsyth, D. (2010). Group dynamics ( $5^{\text {th }}$ ed.). , Belmar, CA: Cengage Learning.

Gosling, D., \& D'Andrea, V. (2001). Quality development: A new concept for higher education. Quality in Higher Education, 7, 7-17. doi:10.1080/13538320120045049

Gray, B. (1989). Collaborating: Finding common ground for multiparty problems. . San Francisco, CA: Jossey-Bass Inc., Publishers.

Great Schools Partnership (2015). Action research. In S. Abbott (Ed.), Glossary of education reform [Online Publication]. Retrieved from http://edglossary.org/action-research/

Hanson, M. P. (2005). Clues to achieving consensus: A leader's guide to navigating collaborative problem solving. Lanham, MD: Rowman \& Littlefield Publishing.

Huisman, J., \& Currie, J. (2004). Accountability in higher education: Bridge over troubled water?. Higher Education, 4, 529. Retrieved from http://www.jstor.org/stable/4151570

Innes, J. E. (1996). Planning through consensus building. Journal of American Planning Association, 65, 460-472.

Innes, J. E., \& Booher, D. E. (1999a). Consensus building and complex adaptive systems: A framework for evaluating collaborative planning. Journal of American Planning Association, 65, 412-423.

Innes, J. E., \& Booher, D. E. (1999b). Consensus building as role playing and bricolage: Toward a theory of collaborative planning. Journal of American Planning Association, 65, 9-26.

Kezar, A. (2012). Bottom-up/top-down leadership: Contradiction or hidden phenomenon. Journal of Higher Education, 83(5), 725-780.Levine, H. G., McGuire, C. H., \& Nattress, W. (1970). The validity of multiple cachievement tests as measures of competence in medicine. American Educational Research Journal, (1), 69-82.

Lorenzi, N. M., \& Riley, R. T. (2000). Managing change: An overview. Journal of the American Medical Informatics Association, $7(2)$. Retrieved from https://www.ncbi.nlm.nih.gov/pmc/articles/PMC61464/https://www.ncbi.nlm.nih.gov/pm c/articles/PMC61464/

Mason, S. G., Holley, D., Wells, A., Jain, A., Wuerzer, T., \& Joshi, A. (2016). An experimentbased methodology to understand the dynamics of group decision making. SocioEconomic Planning Sciences, 56, 14-26. doi:10.1016/j.seps.2016.06.001

Massy, W. (2013, April 11). Initiatives for containing the cost of higher education. Retrieved from American Enterprise Institute website: http://www.aei.org/publication/initiatives-forcontaining-the-cost-of-higher-education/ 
Masters, J. (1995). The history of action research. In I. Hughes (Ed.). Action Research Electronic Reader. Retrieved from http://www.behs.cchs.usyd.edu.au/arow/Reader/rmasters.htm

Meek, J. A., Runshine, D., Young, J., Embree, J., \& Riner, M. (2015). Creating a faculty community that values curricular assessment and improvement: One DNP program's experience. Journal of Professional Nursing, 31(1), 11-17.

Murphy, M. (2016). The tug of war between change and resistance. Educational Leadership, 3(9), 66-70.

Nelson, C. (2010, December 21). Defining academic freedom. Inside Higher Ed. Retrieved from https://www.insidehighered.com/views/2010/12/21/defining-academic-freedom

Pannucci, C. J., \& Wilkins, E. G. (2010). Identifying and avoiding bias in research. Plastic Reconstructive Surgery, 126(2), 619-625. doi: 10.1097/PRS.0b013e3181de24bc

Piderit, S. K. (2000). Rethinking resistance and recognizing ambivalence: A multidimensional view of attitudes toward an organizational change. Academy of Management Review, 25(4), 783-794. doi:10.5465/AMR.2000.3707722

Raiffa, H. (2003). Negotiation analysis: The science and art of collaborative decision making. Cambridge, MA: Belknap Press.

Sadler, R. (2011). Academic freedom, achievement standards and professional identity. Quality in Higher Education, 17(1), 85-100.

Smith, D., \& Eder, D. (2001). Assessment and program review: Linking two processes. Assessment Update, 13(1), 1-15.

Susskind, L., McKearnan, S., \& Thomas-Larner, J. (1999). The Consensus Building Handbook: A Comprehensive Guide to Reaching Agreement. Thousand Oaks, CA: Sage Publications.

Yin, A. C., \& Volkwein, J. F. (2010). Assessing general education outcomes. New Directions for Institutional Research, 79-100.

Yingqiang, Z., \& Yongjian, S. (2016). Quality assurance in higher education: Reflection, criticism, and change. Chinese Education \& Society, 49, 7-19. Doi:10.1080/10611932.2016.1192382 


\section{Appendix A}

\section{Sample Comprehensive Exam Questions}

1) A child uses /s/ and /z/ in the final position of the words gas, mess, and fuzz, but leaves off the sound in the words dogs, peas, and cans. This is an example of a
a. Morphological Disorder
b. Articulation Disorder
c. Cluster reduction
d. Phonological Disorder

2) Syntax and morphology in school-age children are best measured by:
a. MLU calculation
b. Classroom observation
c. T-Unit analysis
d. Phonetic transcription

3) Swabbing the posterior portion of the tongue with salt water and sugar water would assess:
a. Sensory CN X
b. Sensory CN IX
c. Sensory CN V
d. Sensory CN VI

4) Which of the following is not a stuttering modification treatment technique?
a. Pull-out/change-out
b. Anticipatory Prolongation
c. Cancellation
d. Relaxation

5) Maggie, a 4-year-old assessment client has earned a standard score of 96 on the Peabody Picture Vocabulary Test - IV (PPVT-IV). How would you interpret this score?
a. She has average single-word expressive vocabulary skills
b. She has average single-word receptive vocabulary skills
c. She has average semantic-syntactic skills
d. She has below average single-word vocabulary skills

6) Delayed triggering of the pharyngeal swallow and early spillage could be effectively managed/treated by which of the following:
a. Chin tuck
b. Oral motor exercises for improved tongue lateralization
c. Thermal tactile stimulation
d. Mendelsohn maneuver 